\title{
FAILURE MODES AND EFFECT ANALYSIS: A TOOL TO MANAGE PATIENT SAFETY PROACTIVELY
}

\section{Dr S Sridharan *}

\section{Introduction}

The safety of a patient depends on each health professional's ability to "do the right thing." As a health professional continuously works at improving quality, individual performance shifts to "doing the right thing well."1 Assuring the safety of the patient to whom services are provided is an essential dimension of professional performance. The Institute of Medicine (IOM) published a report in year 2000 entitled To Err is Human: Building a Safer Health system. 2 This report describes the risks of medical care in the United States and the documented harm that has occurred because of unsafe practices in the healthcare systems.

A Patient Safety Practice application reduces the probability of adverse events resulting from exposure to the healthcare system across a range of diseases and procedures 1 . The delivery of care and its mode of delivery should have the least potential to cause patient harm and the greatest potential to result in an optimal outcome for the patient. Patients assume that this is what we do when we take care of them.

\section{Systems Approach to Patient Safety Management}

With respect to patient safety, there is a growing recognition that an understanding of the nature and frequency of error is a prerequisite for effective error management. However, several researchers have pointed out that achieving a good understanding of failure in healthcare is hampered by the fact that there is no standard way of defining errors in healthcare, and therefore no standardized classification system 3 .

Anyhow, according to Reason (2000), the systems approach to patient safety management adopts a more sophisticated perspective, focusing not only on the individual, but also on the role of organizational factors. It is acknowledged that in order to understand the roots of individual errors, it is necessary to consider the physical, social and organizational environment in which the individual operates. From the systems perspective, a crucial distinction is made between active and latent failures. 4

Active Failures - These are the proximal causes of adverse events. They nearly always involve individual error or violation and have an immediate negative effect.
Latent Failures - These are likely to be removed in time and space from the focal event, but nevertheless act as contributory factors. Latent failures, also sometimes known as error-provoking conditions, include poor management, poorly maintained equipments, unworkable procedures or short-sighted policies. Researchers found that active failures contribute only to $15 \%$ of all errors and the balance $85 \%$ contribution is from the latent failures.

James Reason's Swiss cheese model, shown in figure 1, offers a widely cited and elegant depiction of the effects of latent failures.

\section{Figure 1: The Swiss Cheese Model of Organizational Safety 4}

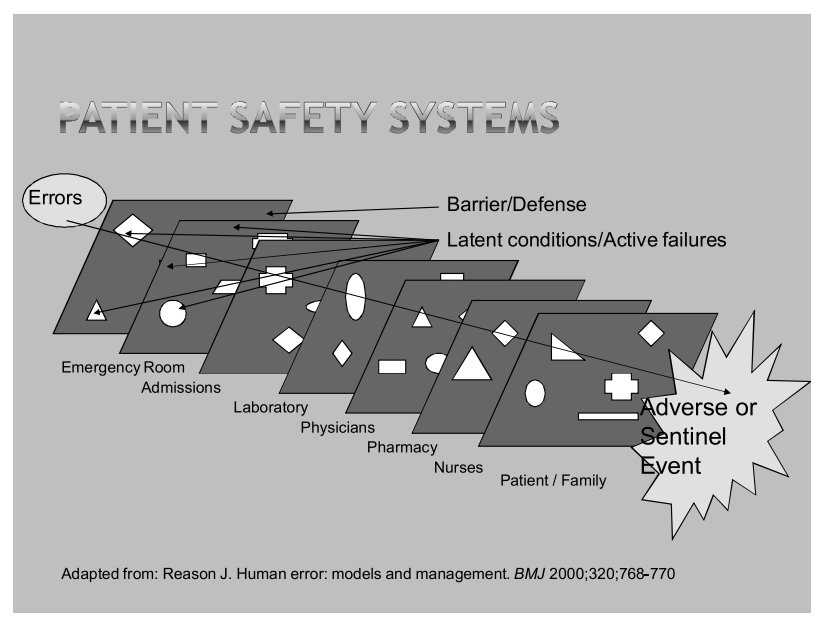

Hence, it is the systems development that is much needed for patient safety improvement. It is therefore necessary to understand patient safety culture to tune the systems towards patient safety. Figure 2 shows the evolution of safety culture.

\section{Figure 2: Evolution of Patient Safety Culture5}

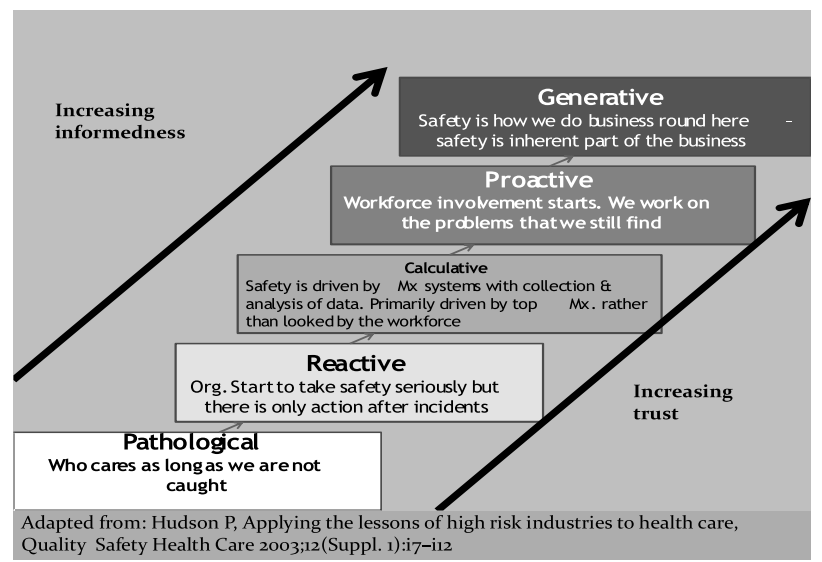


The above figure indicates that the safety culture must move from reactive to proactive. In reactive culture, the organization takes safety seriously and does Root Cause Analysis (RCA) only after the occurrence of an incident. In proactive culture, the organization finds the potential adverse events before its occurrence. One of the tools to identify such adverse events proactively is Failure Modes and Effect Analysis. This article briefly describes such method.

A methodology called Failure Modes and Effect Analysis (FMEA) is a very helpful tool to proactively identify and prioritize errors that could occur in the process, rather than reacting after the incident. FMEA was originally developed by the U.S. military in 1949 to proactively anticipate potential failures and became more widely used in the automotive industry in the 1970s. In some countries, FMEA already tends to be used in hospital transfusion medicine and pharmacy settings, but can be used to improve any process. 6

\section{Failure Modes and Effects Analysis (FMEA)}

An FMEA document is typically built in a spreadsheet and is based on team brainstorming about what could go wrong in their process. As with standardized work (with the initiation of 5S and Kaizen), FMEA is most effectively done by the people who actually work in the process, although the FMEA could be facilitated by someone experienced with that methodology6.

The following steps are used in the FMEA process.

1. Select a Process - When we select a process that process must be of high importance to the organization.

2. Assemble a Team - The team must contain all categories of staff who are actively involved in the process. Preferably there should be $8-10$ members in the team
3. Diagram the Process - It is essential to select only 5-8 highly important activities. The diagram must be linear as far as possible and it is recommended to avoid 'if X, then y splits'. Each activity should describe something which has been done (For example: Medical Officer examines the patient, Consultant writes the operation notes)

4. Brainstorm - The team analyses each activity to identify where the error can occur and ranks each into three categories :

- What is the severity of the error when it occurs?

- What is the likelihood of occurrence?

- How difficult is it to detect the error?

Each category gets a score on a 1-10 scale (low to high) and the scores are multiplied together to give a Risk Priority Number (RPN) for each failure mode. To help prioritize our improvements (assuming we cannot fix everything at once), we sort the failure modes by their RPN score. The failure modes with the highest scores should receive our initial attention. If a failure mode is very likely to occur (score 10), is very hard to detect (score of 10), and would cause a patient death (score of 10), the RPN score would be 1000. Table 1 illustrates this. Table 1

5. Complete the FMEA form - The form which was developed must be completed finalizing the ranks of the activities according to the RPN score. Then use the RPN to determine where to focus your limited resources. To start we are looking for failures that are most severe, occur often, and are hard to detect. Of all the activities which scores highest RPN ranks 1, the activity which scores second highest RPN ranks 2 and so on. The highest priority must be given to the activity that ranks 1 and take necessary action. A sample form is shown below.

\begin{tabular}{|c|c|c|c|c|c|}
\hline \multicolumn{2}{|c|}{ Failures } & \multicolumn{3}{|c|}{ Rankings } & \multirow[b]{3}{*}{$\begin{array}{l}\text { Risk Priority } \\
\text { Number (RPN) } \\
(\mathrm{A}) *(B) *(C)\end{array}$} \\
\hline & & Severity (A) & Occurrence (B) & Detection (C) & \\
\hline $\begin{array}{l}\text { Potential } \\
\text { Mode of } \\
\text { Failure }\end{array}$ & $\begin{array}{l}\text { Potential } \\
\text { Causes } \\
\text { and } \\
\text { Effects } \\
\text { of } \\
\text { Failures }\end{array}$ & $\begin{array}{l}\text { 1=None } \\
\text { 3=Slight } \\
\text { 5=Moderate } \\
\text { 7=Major } \\
\text { 9=Serious } \\
\text { 10=Hazard }\end{array}$ & $\begin{array}{l}\text { 1=Never } \\
3=V \text { Slight } \\
5=\text { Low } \\
7=\text { Mod High } \\
9=V \text { High } \\
\text { 10=Almost } \\
\text { Certain }\end{array}$ & $\begin{array}{l}\text { 1=Certain } \\
3=\text { High } \\
\text { 5=Medium } \\
7=\text { Slight } \\
9=\text { Remote } \\
\text { 10=Almost } \\
\text { impossible }\end{array}$ & \\
\hline
\end{tabular}

Table 1: Risk Priority Number (RPN) in FMEA 


\begin{tabular}{|l|c|c|}
\hline \multicolumn{1}{|c|}{ Activity } & RPN Score & Rank \\
\hline Activity 1 & 168 & 3 \\
\hline Activity 2 & 360 & 1 \\
\hline Activity 3 & 54 & 4 \\
\hline Activity 4 & 210 & 2 \\
\hline
\end{tabular}

\section{References}

1. Shojania KG, Duncan BW, McDonald KM, Watcher RM. Making Health Care Safer: A Critical Analysis of Patient Safety Practices. Evidence report / technology assessment - Number 43, AHRQ Publication 01-E058 July 20, 2001

2. Kohn LT, Coorigan JM, Donaldson MS, eds. To Err Is Human: Building a Safer Health System. Washington. DC: National Academy Press; 2000, p.5

3. Sandars, J. Esmail, A. (2003) The frequency and nature of medical error in primary care: understanding the diversity across studies, Family Practice, 20: pp. 231236

must be redesigned so that errors can be prevented. Introducing checklist, protocols, guidelines are few of those.

7. Analyze and test the new processes - A pilot study should be carried out and analyzed before adapting, institutionalizing and standardizing the process. The team must be flexible to make changes in the plan if there is a necessity.

8. Implement \& monitor redesigned process - Then the redesigned process must be implemented and monitored. The process must be reviewed routinely to improve further.

Using an FMEA is in keeping with the Lean Concept that we have to be open in talking about problems in our work place. FMEA is just a tool. Leadership must take responsibility for creating an environment of openness in the name of patient safety and error prevention.

\section{Conclusion}

For many years, healthcare organizations have relied primarily of people performing their jobs correctly to protect patients from unintended harm. Decades of research, mostly from other industries, especially from airline industry, has proven that most accidents are caused by capable but fallible people working in dysfunctional systems. Healthcare organizations are now borrowing techniques from other industries and using systems approach to improve patient safety.

Patient safety includes the same basic quality management components: measurement, assessment, and improvement. One of the important models is FMEA which is now often used to reduce the chance that harmful mistakes will occur. If this model can be introduced to Sri Lankan hospitals, a large sum of money due to failures can be saved.

4. Reason J. Human error: models and management. BMJ 2000;320;pp. 768-770

5. Hudson P, Applying the lessons of high risk industries to health care, Quality Safety Health Care 2003;12(Suppl. 1):i7-i12

6. Graban Mark, Lean Hospitals, CRC Press, 1st edition, 2009, pp 130-131 